\title{
Agreement between self-assessment of body image and measured body mass index in the Brazilian adult population
}

\author{
Concordância entre auto-avaliação da imagem corporal e o índice \\ de massa corporal medido na população adulta brasileira
}

Luiz Antonio dos Anjos (https://orcid.org/0000-0002-5257-6912) ${ }^{1}$

Cristiane Ferreira Moraes (https://orcid.org/0000-0001-8573-0798) ${ }^{1}$

${ }^{1}$ Laboratório de Avaliação Nutricional e Funcional, Departamento de Nutrição Social, Universidade Federal Fluminense. R. Mário Santos Braga 30, Valonguinho. 24020-140 Niterói RJ Brasil. lanjos@id.uff.br

\begin{abstract}
Silhouettes are used in the self-assessment of one's body size, shape and satisfaction. This technique can be helpful in intervention studies and in household studies in which body size measurements are not feasible. Despite its popularity, few studies have validated the Stunkard Figure Rating Scale (SFRS) to assess body image (BI) or nutritional status (NS). The present study assessed the agreement between self-assessment of $B I$ by SFRS and measured BMI in adults from a national household survey in Brazil ( $n=11$ 247; $57.2 \%$ women, aged 20-99y). The subjects were asked to choose a silhouette from the SFRS that most resembled their current status prior to measures of body mass and stature. BMI-derived NS was then matched to the SFRS. The prevalence of overweight and obesity $(\mathrm{OB})$ was 34.4 and $19.0 \%$, respectively. Weighted kappa between SFRS and BMI was 0.45 and 0.43 and Spearman's correlation coefficient was 0.64 and 0.59 for women and men, respectively. Sex-specific receiver operating curves indicated that the silhouettes correctly (area under the curve $>0.80$ ) identified $O B$ and underweight (UW). In conclusion, SFRS provides only reasonable results when estimating the BMI distribution but it works well to identify $O B$ and $U W$ in the Brazilian adult population.

Key words Body mass index, Body image, Validation studies, Nutrition assessment, Obesity
\end{abstract}

Resumo Silhuetas são usadas na autoavaliação (AA) da forma, satisfação e dimensão corporal (DC) em estudos de intervenção ou inquéritos domiciliares nos quais a medição da DC é inviável. Apesar de sua popularidade, poucos estudos validaram a Escala de Avaliação de Figuras de Stunkard (SFRS) para avaliar a imagem corporal (IC) ou o estado nutricional (EN) em adultos. $O$ presente estudo avaliou a concordância entre a $A A$ da IC pela SFRS e o IMC medido em adultos de um inquérito domiciliar nacional brasileiro ( $n$ = 11 247; 57,2\% mulheres de 20 a 99 anos), em que foram convidados a escolher uma silhueta da SFRS que mais se assemelhasse ao seu estado atual antes de medidas antropométricas serem obtidas. $O E N$, baseado no IMC, foi ajustado à SFRS. As prevalências de sobrepeso $(S)$ e obesidade $(O B)$ foram 34,4 e 19,0\%, respectivamente. O kappa ponderado entre SFRS e IMC foi 0,45 e 0,43 e o coeficiente de correlação de Spearman foi 0,64 e 0,59 para mulheres e homens, respectivamente. As curvas ROC específicas por gênero indicam que as silhuetas identificam corretamente (área abaixo da curva >0,80) OB e baixo peso (BP). Em conclusão, o SFRS fornece apenas resultados razoáveis na estimação da distribuição de IMC, mas funciona bem para identificar $O B$ e $B P$ em adultos brasileiros.

Palavras-chave Indice de massa corporal, Imagem corporal, Estudos de validação, Avaliação nutricional, Obesidade 


\section{Introduction}

Self-assessment of body image is a multidimensional construct by which individuals describe the internal representations of their body structure and physical appearance in relation to themselves and others ${ }^{1}$. This process is strongly influenced by intrinsic (gender and age) and socio-psychological factors such as attitude, culture and nutritional status ${ }^{1-3}$. Various methods, including questionnaires, drawings and body distortion techniques have been used to measure the various components of body image. In recent years, the use of silhouettes has become popular to measure the size, shape and satisfaction of one's body ${ }^{1}$. To this end, the series of silhouettes introduced by Stunkard et al. ${ }^{4}$ to assess the parent's weight status of adoptees in the Danish Adoption Register, later named as the Stunkard Figure Rating Scale (SFRS), have been used extensively both in clinical $^{5,6}$ and epidemiological ${ }^{7,8}$ studies. The method consists of asking subjects to choose one of the 9 silhouettes in the SFRS (1, the thinnest and 9, the heaviest) that best represents their body presently, sometime in the past or that he/she wished they were. The response is later confronted with either informed or measured anthropometric measures, generally the body mass index (BMI), for validation or clinical interpretation. Most published studies have focused on the relationship between the SFRS and BMI to diagnose eating disorders or body distortion/satisfaction and have shown that people, especially women, tend to choose skinner silhouettes than their BMI would suggest ${ }^{1}$.

In many clinical studies, body size is measured and the nutritional status of individuals and populations are determined and used in the development of health intervention strategies, particularly in obesity research. However, these interventions may not work or the subjects may lose interest if they have distorted image of their body $y^{8}$. On the other hand, SFRS may be a surrogate to assess the nutritional status in large household studies in which body size measurements are not feasible. Despite its popularity, very few studies have validated the use of SFRS in comparison to anthropometric measures of different populations $s^{9,10}$. The validation process is very important given the way different populations perceive their body size ${ }^{2,11}$. Many of the validation studies conducted worldwide have identified cultural, gender and ethnical differences in the perception of body image but most used convenience samples, particularly recruit- ing young, college students pursuing health-related degrees ${ }^{1,3,9}$. Thus, the purpose of the present study was to assess the agreement between the SFRS and measured BMI in adults of a probability sample of Brazilian households in 2008.

\section{Material and Methods}

\section{Data source, sampling, and subjects}

The Social Dimensions of Inequality Survey was a population-based household survey carried out by a consortium of universities and research organizations from various regions of Brazil and funded by the Brazilian National Research Council. A total of 12423 heads of households and their spouses living in 8048 permanent private households from both urban and rural settings in Brazil were interviewed between July and December 2008. The subjects of the present analysis are composed of 11247 (6516 women) adults ( $\geq$ 20 years) with complete datasets of anthropometry and self-assessment of body image.

Details of the sampling design have been published elsewhere ${ }^{12}$. In short, the population was divided into domains, defined according to region and setting (urban or rural) so that social indicators for each domain and the population as a whole could be estimated. The sample consisted of 1374 census enumeration areas (CEA) spread in all regions of the country. The estimated number of households in the sample accounted for replacement due to absence from household or refusal to participate in the study in every socioeconomic stratum. Research procedures were in accordance with the Helsinki Declaration for protection of human subjects from research risks and verbal consent of participants was obtained and formally recorded prior to data collection.

\section{Instrument for data collection}

During the household visit the interviewer initially showed the SFRS ${ }^{4}$ printed on a card (one for each sex) and asked the following question: "What is the number that best describes your body today?" After the response, anthropometric measurements were obtained with the participant barefoot and wearing light clothes. Body mass (BM) was measured on a portable solar-powered electronic scale (Tanita HS301W, Tokyo, Japan) to the nearest $0.2 \mathrm{~kg}$ for values between 0 and $100 \mathrm{~kg}$ and $0.5 \mathrm{~kg}$ for values between 100 and $150 \mathrm{~kg}$. Stature (S) was measured in du- 
plicate on a portable wall-mounted stadiometer (WISO, Santa Catarina, Brazil) to the nearest $0.1 \mathrm{~cm}$ and the average used in the analysis. Body mass index (BMI) was calculated as the ratio between BM and squared $S$ in meters.

\section{Analyses}

In order to evaluate the agreement and correlation between measured BMI and self-assessed body image, four groups of silhouettes were arbitrary created. There is no consensus on the relation of the silhouettes to the nutritional status of adults. For instance, Bhuiyan et al. ${ }^{13}$ arbitrarily created 5 groups of silhouettes to represent the nutritional status of the participants $(18-35 y$ of age) of the Bogalusa Heart Study. In this scheme, silhouettes 1 and 2 represented underweight; 3 and 4 , correct body mass; 5 , slightly overweight; 6 and 7, moderately overweight; and 8 and 9, very overweight. Some other studies cite this study but use a 4-group classification: silhouettes 1 and $2 ; 3$ and 4; 5-7; and 8 and $9^{14-18}$. In another study, Sutcliffe et al. ${ }^{19}$ created 3 silhouette groups: normal body mass (1-5); overweight (6 and 7); and obesity ( 8 and 9 ) even though the authors cite the 5 -silhouette groups created by Bhuiyan et al. $^{13}$. For the present analysis, the 4 chosen categories were based on the highest percentage distribution of BMI for each of the 9 silhouettes: a) silhouette $1\left(40 \%\right.$ in the BMI $<20 \mathrm{~kg} / \mathrm{m}^{2}$ category); b) silhouettes $2-4$ (60, 62 and $48 \%$ in the $20 \leq \mathrm{BMI}<25 \mathrm{~kg} / \mathrm{m}^{2}$ category for silhouettes 2,3 and 4, respectively); c) silhouettes 5 (54\%) and 6 $(44 \%)$ in the $25 \leq \mathrm{BMI}<30 \mathrm{~kg} / \mathrm{m}^{2}$ category and d) silhouettes 7-9 (70, 86 and $81 \%$ in the BMI $\geq$ $30 \mathrm{~kg} / \mathrm{m}^{2}$ category for silhouettes 7,8 and 9 , respectively). Likewise, BMI data were grouped in four categories to match the silhouette groups ${ }^{20}$ : a) underweight $(\mathrm{BMI}<20)$, b) healthy BMI $(20 \leq$ BMI $<25$, c) overweight $(25 \leq \mathrm{BMI}<30)$ and $\mathrm{d})$ obesity (BMI $\geq 30$ ). Because of the low frequency of subjects with BMI below $18.5 \mathrm{~kg} / \mathrm{m}^{2}$, BMI cut-off value of $20 \mathrm{~kg} / \mathrm{m}^{2}$ was used to represent underweight.

Statistical analyses consisted of nonparametric statistical procedures to assess the association (Spearman's correlation coefficient) and agreement (simple and weighted Kappa - $k$ ) between BMI and the self-assessed body image classifications. The agreement between BMI and two other classifications using 4 categories (silhouettes $1-2 ; 3-4 ; 5-7 ; 8-9$, Easton et al. ${ }^{14}$ ) or 3 categories (silhouettes 1-5; 6-7; and 8-9, Sutcliffe et al. ${ }^{19}$ ) were performed to ascertain whether the agreement changed when these classifications were used (sensitivity analysis, Velentgas et al. ${ }^{21}$ ). In addition, prevalence and bias adjusted $k$ (PABAK) was calculated as described by Byrt et al. ${ }^{22}$. The interpretation of $k$ and PABAK coefficients was made according to the criteria proposed by Landis and $\mathrm{Koch}^{23}$ as: poor, $<0$; slight, 0-0.20; fair, 0.21-0.40; moderate, 0.41-0.60; substantial, 0.610.80; and almost perfect, 0.81-1.0. Furthermore, the percentage of diagonal agreement, defined as the percentage of subjects who were correctly classified in the same range of measured and self-assessment, was also calculated for each sex.

Receiver operating curves (ROC) were generated using logistic regression to establish the area under the curve (AUC) to determine the ability of the silhouettes to predict obesity and underweight. All statistical analyses were performed using the SAS University Edition 9.4 using the sample weights in accordance to the complex sample design of the study. Significance between the group proportions were determined when the $95 \%$ confidence intervals $(95 \% \mathrm{CI})$ did not overlap.

\section{Results}

Mean (SE) age of the population was $48.8(0.1)$ and overweight corresponded to 33.4 and $38.1 \%$ of the women and men, respectively (data not presented in tables). Obesity was found in $22.5 \%$ of the women and $15.2 \%$ of the men. Healthy BMI comprised $35.4 \%$ of the women and $39.2 \%$ of the men. The frequency of BMI that corresponds to underweight was low in both sexes, with values of $8.7 \%$ and $7.5 \%$ in women and men, respectively.

The distribution of self-assessment body image using the SFRS and measured BMI according to sex is presented in Table 1 . The most selected silhouettes were numbers 4 and 5 , followed by silhouette 3 for both sexes, comprising approximately $61 \%$ of the population (65.8 and $75.9 \%$ of women and men, respectively). The extreme silhouettes (1 and 9) were the least selected. Mean BMI increased as the silhouette numbers increased and all chosen silhouettes had obese subjects.

The BMI distribution of the subjects by chosen SFRS silhouettes is presented in Figure 1. Only $52 \%$ of the women and $30 \%$ of the men who chose silhouette 1 as their current body size were, in fact, underweight. In the other extreme, $83 \%$ of the women and $75 \%$ of the men 
Table 1. Distribution (\%) of self-assessment body image using Stunkard Figure Rating Scale (SFRS) and mean, SE and $95 \%$ confidence interval, minimum $(\mathrm{min})$ and maximal $(\max )$ measured body mass index $\left(\mathrm{BMI}, \mathrm{kg} / \mathrm{m}^{2}\right)$ values of adults ( $\geq 20$ years) from a probability sample of Brazilian households, 2008 .

\begin{tabular}{rrrrrrrrrrr}
\hline \multicolumn{1}{c}{ Women } & \multicolumn{5}{c}{ Men } \\
\hline SFRS & \multicolumn{1}{c}{ \% } & Mean & SE & 95\%CI & Min-Max & \% & Mean & SE & 95\%CI & Min-Max \\
\hline 1 & 3.7 & 20.4 & 0.20 & $20.0 ; 20.8$ & $12.5-35.4$ & 6.3 & 21.6 & 0.16 & $21.3 ; 21.9$ & $14.4-31.9$ \\
2 & 12.2 & 21.5 & 0.10 & $21.3 ; 21.7$ & $13.8-40.0$ & 13.4 & 22.6 & 0.12 & $22.4 ; 22.8$ & $14.6-32.7$ \\
3 & 14.2 & 23.2 & 0.10 & $23.0 ; 23.4$ & $12.6-41.7$ & 17.0 & 24.0 & 0.11 & $23.8 ; 24.2$ & $14.0-34.8$ \\
4 & 24.5 & 25.1 & 0.08 & $24.9 ; 25.3$ & $16.1-48.1$ & 21.6 & 24.5 & 0.10 & $24.3 ; 24.7$ & $16.5-39.0$ \\
5 & 23.1 & 27.8 & 0.10 & $27.6 ; 28.0$ & $14.9-52.6$ & 22.4 & 27.4 & 0.10 & $27.2 ; 27.6$ & $15.1-45.7$ \\
6 & 12.8 & 30.7 & 0.14 & $30.4 ; 31.0$ & $14.1-44.2$ & 10.2 & 29.0 & 0.17 & $28.7 ; 29.4$ & $17.4-45.0$ \\
7 & 6.5 & 33.7 & 0.23 & $33.2 ; 34.1$ & $20.6-53.7$ & 7.6 & 31.3 & 0.23 & $30.9 ; 31.8$ & $19.2-48.4$ \\
8 & 2.2 & 36.7 & 0.55 & $35.3 ; 37.8$ & $18.1-57.8$ & 1.2 & 33.5 & 0.86 & $31.8 ; 35.2$ & $18.8-51.1$ \\
9 & 0.7 & 37.4 & 1.26 & $34.9 ; 40.0$ & $24.1-61.1$ & 0.3 & 31.9 & 1.56 & $28.6 ; 35.2$ & $19.1-45.9$ \\
\hline $95 \% C I=95 \%$ confidence interval. & & & & & & &
\end{tabular}

who chose silhouette 9 were obese. Overweight prevalence increased from SFRS silhouettes 1 to 5-6 and decreased thereafter in both women and men (Figures $1 \mathrm{~A}$ and $\mathrm{B}$ ). The vast majority of both women and men who chose the largest silhouettes (7-9) were obese.

It is worthy noting that among the adults who chose the leanest silhouettes, a few were obese $(0.47$ and $0.78 \%$ of the women and 1.67 and $1.02 \%$ of the men chose silhouettes 1 and 2 , respectively). Women were more likely to underestimate their BMI. About $44 \%$ of overweight women chose silhouettes that represented healthy BMI (silhouettes 2-4 in the SFRS, Table 2). However, almost $77 \%$ of the obese women (and $62 \%$ of men) underestimated their body image by choosing silhouettes $\leq 6$ in the SFRS. The chosen silhouettes that started to comprise the majority $(50 \%)$ of obese subjects were 6 in women and 7 in men. None of the women who chose silhouette 9 were underweight but one man was, frequency that provided a relatively high percentage $(11 \%)$ when it is weighted to represent the population.

Among the obese women, $56.8 \%$ chose SFRS silhouettes 5 or 6 and $32.7 \%$ chose the extreme silhouettes 7 to 9 (Table 2). Approximately $5 \%$ of the overweight women also chose these silhouettes. The majority of women with healthy BMI (78.5\%) chose silhouettes 2 to 4 . Among men, the results were somewhat similar with obese men choosing about the same percentage of silhouettes above 5 (88.9\%; Table 3 ) as women. The diagonal agreement was 54.0 and $55.3 \%$ in women and men, respectively. The weighted $k$ indicated only moderate agreement $(\cong 0.45)$ between the distribution of BMI and the chosen SFRS silhouettes. The adjustment of $k$ for the prevalence and bias (PABAK) did not change the agreement.

The analysis between BMI and the two other silhouette classifications yielded lower PABAK values both for the Easton et al. ${ }^{14}$ classification (0.404; $95 \% \mathrm{CI}=0.390-0.418$ for women and $0.294 ; 0.275-0.312$ for men) or the Sutcliffe et al. ${ }^{19}$ classification $(0.277 ; 0.258-0.295$ for women and $0.313 ; 0.292-0.334$ for men).

The ability of the silhouettes to identify obesity or underweight was assessed by sex-specific ROCs (Figure 2). The AUC of the figures indicates that the silhouettes correctly identify obesity $(0.863$ and 0.846 for women and men respectively, Figure $2 \mathrm{~A})$ and underweight $(0.859$ and 0.800 for women and men respectively (Figure $2 \mathrm{~B})$.

\section{Discussion}

The results of the present survey confirmed the high prevalence of overweight and obesity in the adult population previously documented in Bra$\mathrm{zil}^{24}$. In addition to the nutritional status profile of the adult population, the present study is the first attempt to explore the self-assessment of body image using SFRS in a nationwide probability sample of adults in Brazil. The results show a large variability of BMI in each of the SFRS. The SFRS was developed to estimate the parent's weight status of Caucasian twins in Denmark in a genetic study of obesity ${ }^{4}$. Furthermore, in the original work there was no description of the 


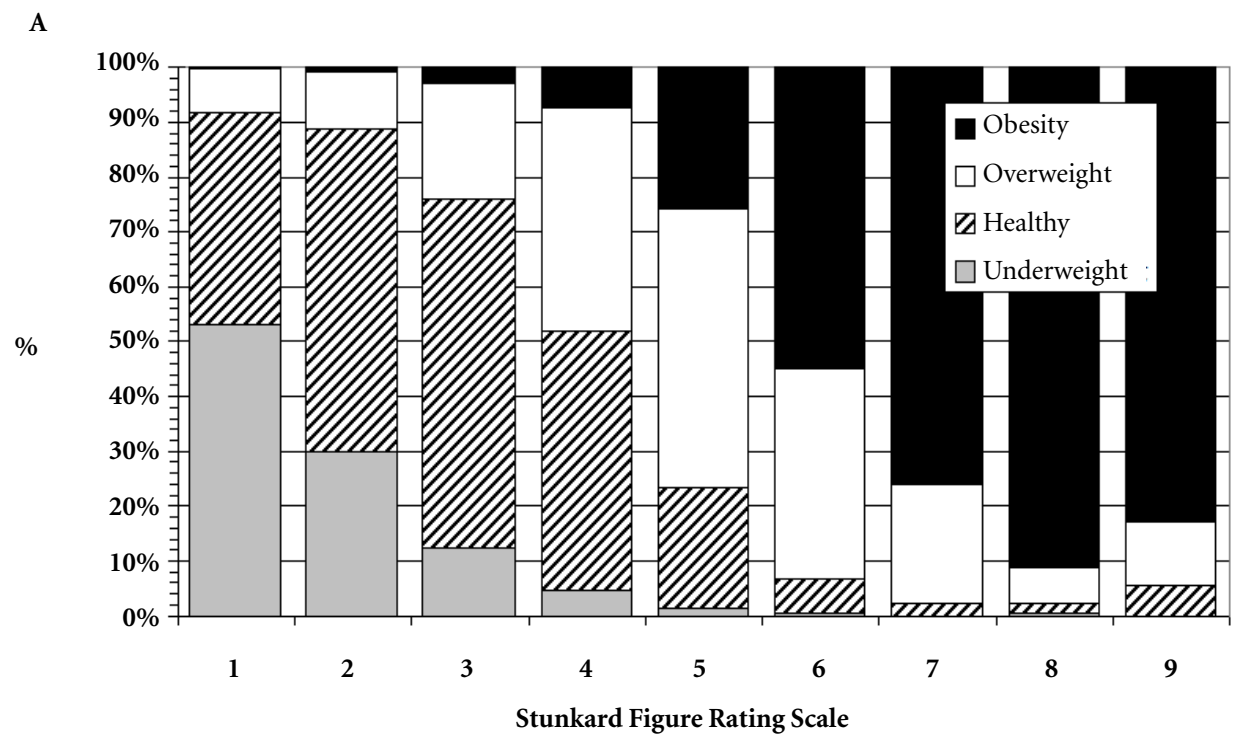

B

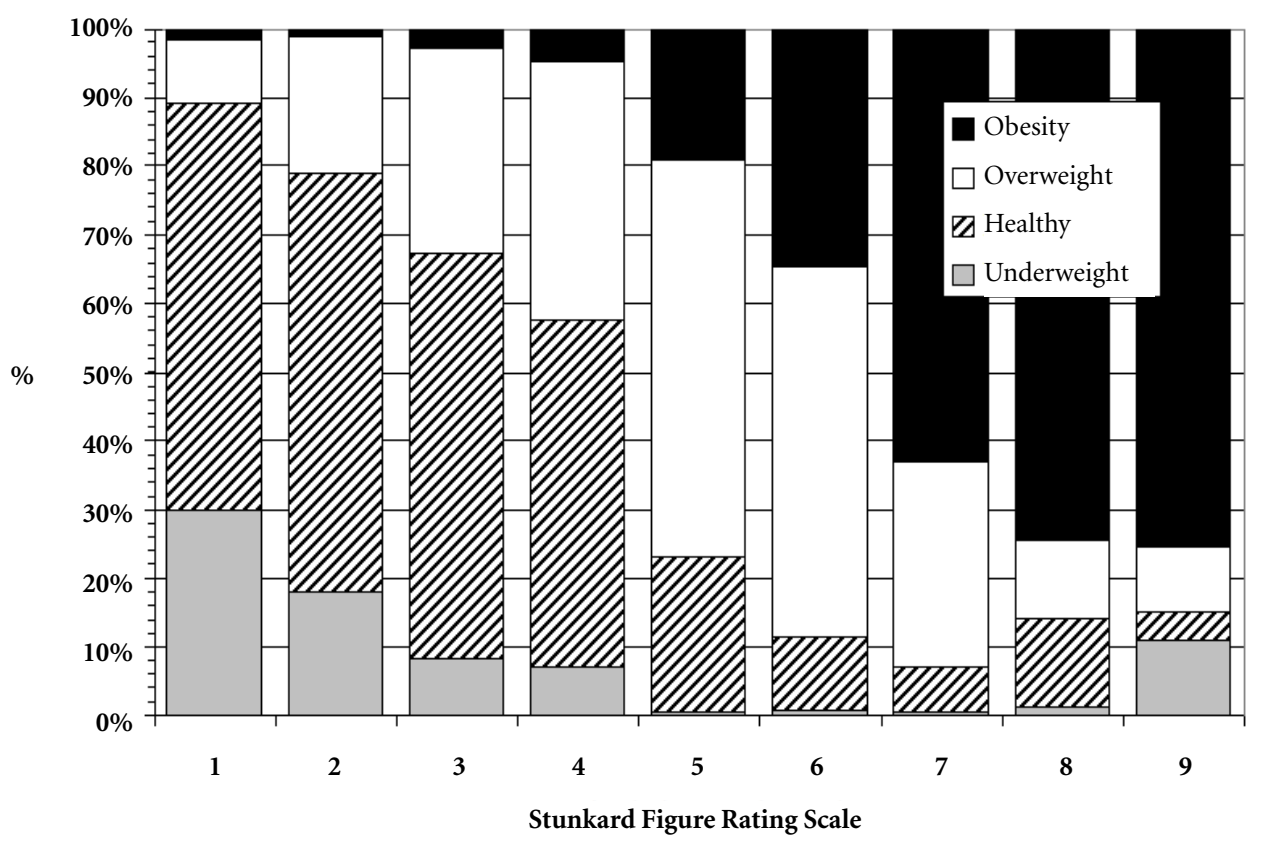

Figure 1. Distribution of body mass index (BMI, $\mathrm{kg} / \mathrm{m} 2)$ in relation to the Stunkard Figure Rating Scale (SFRS) silhouettes ( 1 to 9 ) of adult ( $\geq 20$ years) women (A) and men (B) from a probability sample of Brazilian households, 2008.

anthropometric characteristics of the drawn silhouettes, how they were created and what they represented. In a later study, there was an attempt to describe normative self-reported body size data (body mass and stature) for the SFRS ${ }^{25}$ in a large sample of Caucasians (16 728 females and 
Table 2. Percentage distribution (95\% confidence interval) of self-assessment of body image using the Stunkard Figure Rating Scale (SFRS) in relation to measured body mass index (BMI, $\left.\mathrm{kg} / \mathrm{m}^{2}\right)$ of adult women ( $\geq 20$ years) from a probability sample of Brazilian households, 2008.

\begin{tabular}{lrrrrr}
\hline \multirow{2}{*}{$\begin{array}{c}\text { Measured BMI } \\
(\mathbf{k g} / \mathbf{m} 2)\end{array}$} & \multicolumn{5}{c}{ Stunkard Figure Rating Scale } \\
\cline { 2 - 6 } & $\mathbf{1}$ & $\mathbf{2 , 3 , 4}$ & $\mathbf{5 , 6}$ & $\mathbf{7 , 8 , 9}$ & \multicolumn{1}{c}{ Total (\%) } \\
\hline$<20$ & 22.5 & 73.6 & 3.8 & 0.0 & 8.7 \\
$20-24.9$ & $(18.35 ; 26.61)$ & $(69.19 ; 78.08)$ & $(1.62 ; 6.05)$ & $(0.00 ; 0.14)$ & $(7.89 ; 9.57)$ \\
& 4.1 & 78.5 & 16.7 & 0.7 & 35.4 \\
$25-29.9$ & $(3.14 ; 5.11)$ & $(76.40 ; 80.65)$ & $(14.71 ; 18.63)$ & $(0.28 ; 1.08)$ & $(33.92 ; 36.78)$ \\
& 0.9 & 43.7 & 50.5 & 5.0 & 33.0 \\
$\geq 30$ & $(0.39 ; 1.41)$ & $(41.10 ; 46.25)$ & $(47.87 ; 53.07)$ & $(3.84 ; 6.07)$ & $(31.60 ; 34.41)$ \\
& 0.1 & 10.4 & 56.8 & 32.7 & 22.9 \\
Total & $(0.00 ; 0.21)$ & $(8.54 ; 12.26)$ & $(53.73 ; 59.87)$ & $(29.80 ; 35.64)$ & $(21.67 ; 24.17)$ \\
& 3.7 & 51.0 & 35.9 & 9.4 & 100 \\
\hline
\end{tabular}

Spearman correlation coefficient : $0.64 ;$ CI $95 \%=0.62 ; 0.65$ ( $p<0.01$ ), Simple Kappa: 0.32 ; CI $95 \%=0.30 ; 0.34$, Weighted Kappa: 0.45; CI 95\% $=0.44 ; 0.47$, Prevalence and bias adjusted Kappa (PABAK): 0.38; CI 95\% $=0.37 ; 0.40$, Diagonal agreement $=$ $54.0 \%$, Agreement above diagonal $=14.4 \%$, Agreement below diagonal $=31.6 \%$.

Table 3. Percentage distribution (95\% confidence interval) of self-assessment of body image using the Stunkard Figure Rating Scale (SFRS) in relation to measured body mass index (BMI, $\left.\mathrm{kg} / \mathrm{m}^{2}\right)$ of adult men ( $\geq 20$ years) from a probability sample of Brazilian households, 2008.

\begin{tabular}{lrrrrr}
\hline \multirow{2}{*}{$\begin{array}{c}\text { Measured BMI } \\
(\mathbf{k g} / \mathbf{m} 2)\end{array}$} & \multicolumn{5}{c}{ Stunkard Figure Rating Scale } \\
\cline { 2 - 6 } & $\mathbf{1}$ & $\mathbf{2 , 3 , 4}$ & $\mathbf{5 , 6}$ & $\mathbf{7 , 8 , 9}$ & \multicolumn{1}{c}{ Total (\%) } \\
\hline$<20$ & 24.8 & 71.0 & 3.0 & 1.1 & 7.6 \\
$20-24.9$ & $(19.42 ; 30.28)$ & $(65.32 ; 76.71)$ & $(1.03 ; 4.93)$ & $(0.00 ; 2.55)$ & $(6.66 ; 8.52)$ \\
& 9.4 & 73.4 & 15.5 & 1.7 & 39.6 \\
$25-29.9$ & $(7.76 ; 11.01)$ & $(70.95 ; 75.84)$ & $(13.52 ; 17.52)$ & $(0.97 ; 2.42)$ & $(37.89 ; 41.30)$ \\
& 1.5 & 42.7 & 49.2 & 6.5 & 37.4 \\
$\geq 30$ & $(0.89 ; 2.17)$ & $(39.88 ; 45.47)$ & $(46.42 ; 52.07)$ & $(5.18 ; 7.91)$ & $(35.74 ; 39.10)$ \\
& 0.7 & 10.3 & 50.7 & 38.2 & 15.4 \\
Total & $(0.04 ; 1.32)$ & $(7.58 ; 12.12)$ & $(46.25 ; 55.20)$ & $(33.91 ; 42.59)$ & $(14.13 ; 16.66)$ \\
& 6.3 & 52.0 & 32.6 & 9.1 & 100 \\
\hline
\end{tabular}

Spearman correlation coefficient: $0.59 ;$ CI $95 \%=0.57 ; 0.61$ ( $<<0.01$ ); Simple Kappa: 0.31 ; CI 95\% $=0.29 ; 0.34$; Weighted Kappa: $0.43 ; \mathrm{CI} 95 \%=0.41 ; 0.45$; Prevalence and bias adjusted Kappa (PABAK): $0.40 ;$ CI $95 \%=0.38 ; 0.42$; Diagonal agreement $=55.3 \%$; Agreement above diagonal $=15.0 \%$; Agreement below diagonal $=29.7 \%$.

11366 males, 18-100y of age). Mean BMI values of the SFRS silhouettes chosen by the Brazilian adults were different from those presented by $\mathrm{Bu}$ lik et al. ${ }^{25}$. From silhouettes 1 to 6 mean BMI values were higher for both sexes and lower for the largest silhouettes (7, 8 and 9). However, the silhouettes that comprised most of the obese adults were the same in the two studies.

There is very little information on BMI mean values according to the SFRS distribution in population-based studies around the world. In a large sample $(n=2339$, of whom 1247 were women) of adults (20-69y), Kaufer-Horwitz et al. ${ }^{26}$ also described mean BMI values of apparently healthy Mexican mestisos. In comparison to the Brazilians, Mexican women had higher BMI mean values up to silhouette 6 (ranging from 0.1 to $\left.0.7 \mathrm{~kg} / \mathrm{m}^{2}\right)$ but were higher thereafter $(<0.6$, 2.1 and $1.9 \mathrm{~kg} / \mathrm{m}^{2}$ in the last three silhouettes). In men, there was no tendency but the Mexicans who chose silhouette 1 had lower BMI $(<$ $\left.1.8 \mathrm{~kg} / \mathrm{m}^{2}\right)$ but the ones who chose silhouette 9 had much higher mean BMI $\left(>3.2 \mathrm{~kg} / \mathrm{m}^{2}\right)$ than Brazilians. These differences, along with cultural, gender, ethnical, and cognitive factors ${ }^{14}$, will impact the self perception of body image. Indeed, 

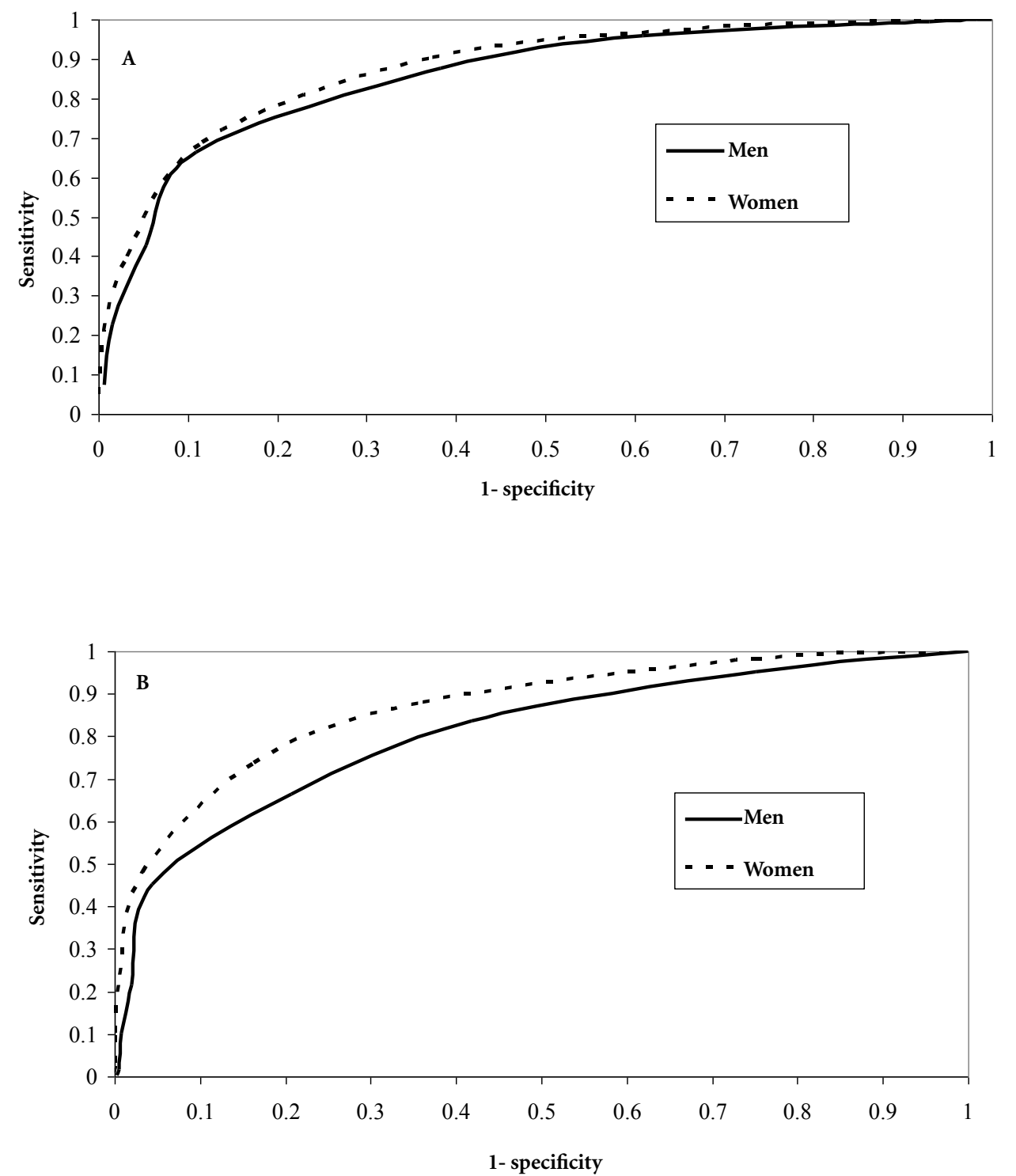

Figure 2. Receiver operating curves (ROC) and the area under the curve of the ability of the Stunkard Figure Rating Scale (SFRS) silhouettes to identify obesity (body mass index - BMI $\geq 30 \mathrm{~kg} / \mathrm{m}^{2}-\mathrm{A}$ ) and underweight $\left(\mathrm{BMI}<20 \mathrm{~kg} / \mathrm{m}^{2}-\mathrm{B}\right)$ of adults ( $\geq 20$ years) from a probability sample of Brazilian households, 2008.

more Mexican men (74.8\%) and women (68.5\%) chose silhouettes 4, 5 and 6 than their Brazilian counterparts.

Self-assessment of body image and measured BMI found in the present study revealed poorer agreement than the results in small convenient samples of adults in the country. For instance, Scagliusi et al. ${ }^{9}$ studied the discriminant and concurrent validity of the SFRS in 82 female college students with no history of eating disorders and obtained higher Spearman's correlation coefficient ( $\mathrm{CC}=0.76$ ) between self-assessment and measured BMI. In fact, a recent review has indicated that most of the studies conducted in the country comprised female college students or adolescents using non-validated instruments ${ }^{27}$. 
Higher CCs were also observed in studies in other countries. Nagasaka et al. ${ }^{28}$ observed Spearman's CCs of 0.80 and 0.73 in samples of Japanese women $(n=1093)$ and men $(n=4$ 808), respectively, almost the same values that Bullik et al. ${ }^{25}$ reported in their population-based normative data for Caucasians. In the Mexican mestisos, the CCs were lower but a little higher in women $(0.766)$ in comparison to men $(0.702)^{26}$.

SFRS have also been applied in special populations ${ }^{7,19,29}$. For example, Bays et al. ${ }^{7}$ compared self-assessment body image of diabetics and non-diabetics $(n=13$ 887) in the US Study to Help Improve Early Evaluation and Management of Risk Factors Leading to Diabetes (SHIELD). The Spearman's CCs were 0.73 for the diabetic and 0.74 for the non-diabetic men. In women, the values were 0.76 and 0.82 , respectively. In a large sample of women $(n=91815)$, Tehard et al. ${ }^{29}$ described a CC of 0.78 between measured BMI and SFRS and concluded that SFRS are useful but they should be interpreted with caution particularly in overweight women.

In a recent systematic review, Moraes et al. ${ }^{1}$ have indentified that most validation studies using the body image self-assessment technique employed CCs in their analyses. Measures of agreement would seem more appropriate when using the SFRS but it is not clear which BMI one would expect to represent each silhouette in the SFRS, a fundamental issue in such analysis. In the present study, the silhouettes were grouped into 4 categories to match the $4 \mathrm{BMI}$ groups to represent the nutritional status of the population. The weighted $k$ and PABAK values presented no major differences between sexes or age in the present study and represented only moderate agreement.

The same analysis using other grouping of silhouettes for the same purpose yielded lower values of all estimates of agreement ( $k$, weighted $k$, and PABAK). Thus, it would seem that the classification used in the present analysis may be useful in studies in Brazil. Maupin \& Hruschka ${ }^{30}$ also documented moderate agreement $(k=0.485)$ between SFRS and BMI in a semi-rural Guatemalan sample of 92 non-pregnant women. Similar values were described by Sutcliffe et al. ${ }^{19}$ in 543 adult men and women from the Johns Hopkins Hospital Outpatient Center undergoing colonoscopy. No study was found in which the PABAK estimate was used as estimates of agreement between self-assessment body image and BMI. The equivalent and moderate agreement of PABAK indicates that there were no imbalance caused by differences in the prevalence and bias ${ }^{22}$.
The percentages of diagonal agreement were similar for both sexes $(>50 \%)$ indicating that about half of individuals selected silhouettes consistent with measured BMI. Thus, taken together, these results show that approximately $30 \%$ of adult Brazilian women and men underestimated their body image. However, the ROCs indicate that the SFRS silhouettes accurately identify obesity and underweight in Brazilian adults. The AUC observed in the Brazilian population is in agreement to the values described in other studies. For example, Kaufer-Horwitz et al. ${ }^{26}$ found AUC values above 0.84 for the accuracy of ROC to detect both overweight or obesity in the Mexican Mestiso adult sample. Maupin \& Hruschka ${ }^{30}$ described similar AUC values (0.853 and 0.832 for overweight and obesity, respectively) in Guatemalan women. In Bulik et al.'s report ${ }^{25}$, AUC was 0.93 and 0.88 for the identification of obesity in women and men. The values for thinness was 0.87 and 0.88 , respectively. Silhouette 6 best represented the optimal cut-off for obesity and silhouette 4 best identified thinness $(\mathrm{BMI}<21)$.

In clinical settings, disagreement between measured BMI and self-assessed body image might provide insights on the psychological health, prognosis of treatment and help identify individuals who have a distorted notion of their nutritional status ${ }^{16,31-33}$. For example, individuals with healthy BMI that select thinner silhouettes may be more susceptible to negative behaviors such as the adoption of restrictive diets or even develop eating disorders. On the other hand, overweight and obesity individuals that underestimate their BMI may not recognize the need to control their body size and, therefore, they may present risk of developing obesity-related diseases themselves or jeopardize their children's BMI trajectories ${ }^{34}$. van Ploeg et al. ${ }^{35}$ have put forward the hypothesis that inadequate self-assessment of body image by overweight or obesity individuals may be the reason for their status because they may be more reluctant to adhere to healthy lifestyles. Indeed, Lynch et al. ${ }^{8}$ have demonstrated that obese women who perceived themselves as obese gained less weight over a period of 13 years in the Coronary Artery Risk Development in Young Adults (CARDIA) Study. In a sample of 2082 middle-aged and older Danish Caucasian women and men of the longitudinal ADDITION-PRO cohort study, Bjerggaard et al. ${ }^{17}$ showed that obese women and overweight men who identified themselves on a higher body image score were at a significantly lower risk of type 2 diabetes. The authors concluded that self-as- 
sessed body image can be a valuable tool when assessing the risk for type 2 diabetes.

This study has some strengths but also some limitations. The positive aspects of the study were that it: 1) was conducted in a large number of adults from a probability sample of households from all areas in Brazil in whom anthropometry was measured and 2) used a complex sampling design which was incorporated in all analyses allowing the results to represent the body perception of the Brazilian adult population. However, the four groups of silhouettes used to test the agreement between the SFRS and the nutritional status of the population were created arbitrarily and could be considered a limitation of the study. Nonetheless, the classification yielded higher $k$ values than oth- er arbitrary grouping of silhouettes. Another intrinsic negative aspect of this kind of study is that BMI is used as the criterion for the classification of nutritional status. This is particularly important when dealing with obesity. Furthermore, the focus on weight of the subjects alone may obscure the more important focus on healthy lifestyle behaviors ${ }^{36}$. Thus, additional studies should be conducted to understand the role of the technique of self-assessment of body image in the diagnosis of the distorted image and its association with health in the Brazilian adult population.

In conclusion, SFRS provide only reasonable results when estimating the BMI distribution but it works well to identify obesity and underweight of the Brazilian adult population.

\section{Collaborations}

LA Anjos participated in the design of the survey, proposed and conducted the analyses. CF Moraes reviewed the literature, conducted some analyses of the data and drafted the first version of the manuscript. Both authors contributed to the interpretation of the data and approved the final version of the manuscript.

\section{References}

1. Moraes CF, Anjos LA, Marinho S. Development, adaptation and validation of silhouette scales for self-assessment of nutritional status: a systematic review. Cad Saude Publica 2012; 28(1):7-19.

2. Bibiloni MD, Coll JL, Pich J, Pons A, Tur JA. Body image satisfaction and weight concerns among a Mediterranean adult population. BMC Public Health $2017 ; 17(1): 39$.

3. Essayli JH, Murakami JM, Wilson RE, Latner JD. The Impact of weight labels on body image, internalized weight stigma, affect, perceived health, and intended weight loss behaviors in normal-Weight and overweight college women. Am J Health Promot 2017; 31(6):484-490

4. Stunkard AJ, Sørensen T, Schulsinger F. Use of the Danish Adoption Register for the study of obesity and thinness. In: Kety S, Roland L, Sidman R, Matthysse S, editors. The Genetics of Neurological and Psychiatric Disorders. New York: Raven Press; 1983. p. 115-120.

5. Conti MA, Ferreira ME, de Carvalho PH, Kotait MS Paulino ES, Costa LS, Teixeira PC, Cordás TA, Scagliusi FB. Stunkard figure rating scale for Brazilian men. Eat Weight Disord 2013; 18(3):317-322.

6. Morotti E, Battaglia B, Paradisi R, Persico N, Zampieri M, Venturoli S, Battaglia C. Body mass index, Stunkard Figure Rating Scale, and sexuality in young Italian women: a pilot study. J Sex Med 2013 10(4):1034-1043.

7. Bays HE, Bazata DD, Fox KM, Grandy S, Gavin 3rd JR; SHIELD Study Group. Perceived body image in men and women with type 2 diabetes mellitus: correlation of body mass index with the figure rating scale. Nutr J 2009; 8:57.

8. Lynch E, Liu K, Wei GS, Spring B, Kiefe C, Greenland P. The relation between body size perception and change in body mass index over 13 years: the Coronary Artery Risk Development in Young Adults (CARDIA) study. Am J Epidemiol 2009; 169(7):857-866. 
9. Scagliusi FB, Alvarenga M, Polacow VO, Cordás TA, Oliveira Queiroz GK, Coelho D, Philippi ST, Lancha Júnior AH. Concurrent and discriminate validity of the Stunkard's Figure Rating Scale adapted into Portuguese. Appetite 2006; 47(1):77-82.

10. Sand AS, Furberg AS, Lian OS, Nielsen CS, Pettersen G, Winther A, Emaus N. Cross-sectional study of the differences between measured, perceived and desired body size and their relations with self-perceived health in young adults: The Tromsø Study - Fit Futures 2. Scand J Public Health 2017; 45(3):322-330.

11. Ejike CE. Body shape dissatisfaction is a 'normative discontent' in a young-adult Nigerian population: A study of prevalence and effects on health-related quality of life. J Epidemiol Glob Health 2015; 5(4 Supl. 1):S19-26.

12. Flor LS, Laguardia J, Campos MR. Intergenerational social mobility and health in Brazil: analyzing the "Social Dimensions of Inequalities Survey (PDSD)", 2008. Cien Saude Colet 2014; 19(6):1869-1880.

13. Bhuiyan AR, Gustat JR, Srinivasan SR, Berenson GS. Differences in Body Shape Representations among Young Adults from a Biracial (Black-White), Semirural Community: The Bogalusa Heart Study. Am J Epidemiol 2003; 158(8):792-797

14. Easton JF, Stephens CR, Román Sicilia H. The effect of a medical opinion on self-perceptions of weight for Mexican adults: perception of change and cognitive biases. BMC Obes 2017; 4:16.

15. Frayon S, Cavaloc Y, Wattelez G, Cherrier S, Touitou A, Zongo P, Yacef K, Caillaud C, Lerrant Y, Galy O. Body image, body dissatisfaction and weight status of Pacific adolescents from different ethnic communities: a cross-sectional study in New Caledonia. Ethn Health 2020; 25(2):289-304.

16. Nikniaz Z, Mahdavi R, Amiri S, Ostadrahimi A, Nikniaz L. Factors associated with body image dissatisfaction and distortion among Iranian women. Eat Behav 2016; 22:5-9.

17. Bjerggaard M, Philipsen A, Jørgensen ME, Charles M, Witte DR, Sandbæk A, Lauritzen T, Færch K. Association of self-perceived body image with body mass index and type 2 diabetes-The ADDITION-PRO study. Prev Med 2015; 75:64-69.

18. Prioreschi A, Wrottesley SV, Cohen E, Reddy A, SaidMohamed R, Twine R, Tollman SM, Kahn K, Dunger DB, Norris SA. Examining the relationships between body image, eating attitudes, BMI, and physical activity in rural and urban South African young adult females using structural equation modeling. PLoS One 2017; 12(11):e0187508.

19. Sutcliffe CG, Schultz K, Brannock JM, Giardiello FM, Platz EA. Do people know whether they are overweight? Concordance of self-reported, interviewer-observed, and measured body size. Cancer Causes Control 2015; 26(1):91-98.

20. World Health Organization (WHO). Obesity: Preventing and Managing the Global Epidemic. Report of a WHO Consultation. Geneva: WHO; 2000. [WHO Technical Report Series 894]

21. Velentgas P, Dreyer NA, Nourjah P, Smith SR, Torchia MM, editors. Developing a Protocol for Observational Comparative Effectiveness Research: A User's Guide. Rockville: Agency for Healthcare Research and Quality; 2013. [AHRQ Publication No. 12(13)-EHC099]
22. Byrt T, Bishop J, Carlin JB. Bias, prevalence and kappa. J Clin Epidemiol 1993; 46(5):423-429.

23. Landis JR, Koch GG. The measurement of observer agreement for categorical data. Biometrics 1977; 33(1):159-174.

24. Instituto Brasileiro de Geografia e Estatística (IBGE). Pesquisa de Orçamentos Familiares 2008-2009. Antropometria e Estado Nutricional de Crianças, Adolescentes e Adultos no Brasil. Rio de Janeiro: IBGE; 2010.

25. Bulik CM, Wade TD, Heath AC, Martin NG, Stunkard AJ, Eaves LJ. Relating body mass index to figural stimuli: population-based normative data for Caucasians. Int J Obes Relat Metab Disord 2001; 25(10):1517-1524.

26. Kaufer-Horwitz M, Martínez J, Goti-Rodríguez LM, Avila-Rosas H. Association between measured BMI and self-perceived body size in Mexican adults. Ann Hum Biol 2006; 33(5-6):536-545.

27. Laus MF, Kakeshita IS, Costa TM, Ferreira ME, Fortes LS, Almeida SS. Body image in Brazil: recent advances in the state of knowledge and methodological issues. Rev Saude Publica 2014; 48(2):331-346.

28. Nagasaka K, Tamakoshi K, Matsushita K, Toyoshima $H$, Yatsuya H. Development and validity of the Japanese version of body shape silhouette: relationship between self-rating silhouette and measured body mass index. Nagoya J Med Sci 2008; 70(3-4):89-96.

29. Tehard B, van Liere MJ, Com Nougué C, Clavel-Chapelon F. Anthropometric measurements and body silhouette of women: validity and perception. J Am Diet Assoc 2002; 102(12):1779-1784.

30. Maupin JN, Hruschka DJ. Assessing the accuracy of two proxy measures for BMI in a semi-rural, low-resource setting in Guatemala. BMC Public Health 2014, 14:973.

31. Zheng Y, Song M, Manson JE, Giovannucci EL, Hu FB. Group-Based Trajectory of Body Shape From Ages 5 to 55 Years and Cardiometabolic Disease Risk in 2 US Cohorts. Am J Epidemiol 2017; 186(11):1246-1255.

32. Chen Y, Liu L, Zhou Q, Imam MU, Cai J, Wang Y, Qi M, Sun P, Ping Z, Fu X. Body mass index had different effects on premenopausal and postmenopausal breast cancer risks: a dose-response meta-analysis with 3,318,796 subjects from 31 cohort studies. $B M C P u$ blic Health 2017; 17(1):936.

33. Acevedo P, López-Ejeda N, Alférez-García I, Martínez -Álvarez JR, Villarino A, Cabañas MD, Marrodán MD. Body mass index through self-reported data and body image perception in Spanish adults attending dietary consultation. Nutrition 2014; 30(6):679-684.

34. Duchin O, Marin C, Mora-Plazas M, Villamor E. Maternal body image dissatisfaction and BMI change in school-age children. Public Health Nutr 2016; 19(2):287-292.

35. van Ploeg ML, Chang HH, Lin BH. Over, under or about right: misperceptions of body weight among food stamp participants. Obesity 2008; 16(9):21202125.

36. Penney TL, Kirk SF. The health at every size paradigm and obesity: missing empirical evidence may help push the reframing obesity debate forward. $\mathrm{Am} \mathrm{J} \mathrm{Pu}$ blic Health 2015; 105(5):e38-42.

Article submitted 09/10/2017

Approved 14/11/2018

Final version submitted 16/11/2018 